\title{
RNA Interference of Dual Oxidase in the Plant Nematode Meloidogyne incognita
}

\author{
Manjula Bakhetia, Wayne Charlton, Howard J. Atkinson, and Michael J. McPherson \\ Centre for Plant Sciences, Faculty of Biological Sciences, University of Leeds, Leeds LS2 9JT, U.K. \\ Submitted 8 September 2004. Accepted 20 June 2005.
}

\begin{abstract}
RNA interference (RNAi) is a powerful tool for the analysis of gene function in model organisms such as the nematode Caenorhabditis elegans. Recent demonstrations of RNAi in plant parasitic nematodes provide a stimulus to explore the potential of using RNAi to investigate disruption of gene function in Meloidogyne incognita, one of the most important nematode pests of global agriculture. We have used RNAi to examine the importance of dual oxidases (peroxidase and NADPH oxidase), a class of enzyme associated with extracellular matrix cross-linking in $C$. elegans. RNAi uptake by $M$. incognita juveniles is highly efficient. In planta infection data show that a single 4 -h preinfection treatment with double-stranded RNA derived from the peroxidase region of a dual oxidase gene has effects on gene expression that are phenotypically observable 35 days postinfection. This RNAi effect results in a reduction in egg numbers at 35 days of up to $70 \%$. The in vitro feeding strategy provides a powerful tool for identifying functionally important genes, including those that are potential targets for the development of new agrochemicals or transgenic resistance strategies.
\end{abstract}

Additional keyword: octopamine.

Plant nematodes represent a major threat to world agriculture that costs an estimated $\$ 125$ billion per annum (Chitwood 2003). Globally, the most damaging plant nematodes are the endoparasitic root-knot nematodes (Meloidogyne spp.) that display broad host-plant specificity. They have considerable adverse effects on both agribusiness and subsistence cropping in subtropical and tropical regions. Strategies to control a pest or parasite should be specific and potent while innocuous to the host plant, nontarget organisms, or its subsequent consumer. We have previously developed transgenic resistance, based on root-specific expression of cystatins (Lilley et al. 1999; McPherson et al. 1997; Urwin et al. 1995), that provides around $70 \%$ resistance in the field (Urwin et al. 2001). Durable resistance, however, is likely to require stacked resistance traits within an integrated pest management system (Atkinson et al. 2003). We are, therefore, interested in identifying other target proteins that will interfere with nematode development.

A major obstacle to the study of gene function in plant nematodes is their obligate biotrophic nature requiring culture on plant roots with a life cycle of several weeks. By contrast, the

Corresponding author: M. J. McPherson; Telephone: +44 (0)113 343 2595; Fax: +44 (0)113 343 3167; E-mail: m.j.mcpherson@leeds.ac.uk

Nucleotide sequence data for the Miduox clone is available in the GenBank database under accession number DQ082753. free-living nematode Caenorhabditis elegans can be cultured in vitro and has a 3-day life cycle, and a range of manipulative tools are available (Riddle et al. 1997). The discovery that $C$. elegans gene expression can be inhibited by RNA interference (RNAi) has revolutionized the molecular characterization of this nematode, making studies of gene function during development relatively simple (Fire et al. 1998; Fridkin et al. 2004; Kamath et al. 2003; Maeda et al. 2001; Tabara et al. 1998; Timmons et al. 2001, 2003). There has been a report of successful RNAi in cyst nematodes Globodera pallida and Heterodera glycines, which parasitize potato and soybean, respectively (Urwin et al. 2002). Nonfeeding J2s were induced to take up dsRNA from solution containing the neuroactive compound octopamine. The fluorescent dye fluorescein isothiocyanate (FITC) provided a marker for uptake from solution, and 10 to $15 \%$ of individuals showed oral uptake. Plant infection studies showed that inhibition of cysteine protease gene expression showed a $40 \%$ reduction in the number of nematodes at 21 days postinfection (dpi). For the C-type lectin there were $55 \%$ fewer nematodes recovered from plants at 14 days (Urwin et al. 2002).

A recent study has also demonstrated the ability to elicit an RNAi response by soaking the eggs of Meloidogyne artellia. The target in this case was a chitin synthase required during development of the eggs (Fanelli et al. 2005).

We have an interest in the extracellular matrix (ECM) of nematodes, which comprises the basement membrane and cuticle. The nematode cuticle is the exoskeleton responsible for determination of shape, mobility, and permeability and acts as a barrier to the environment (Blaxter and Robertson 1998). It is synthesized by the underlying hypodermis, to which it is connected by hemidesmosomes. The major structural components are cuticular collagens and noncollagen components termed cuticulin (Blaxter and Robertson 1998; Johnstone 2000). In plant nematodes, the cuticle undergoes morphological changes upon parasitism, with a more homogenous rather than zoned appearance and altered collagen gene expression (Wang et al. 1998). There remains much to determine about the molecular and biochemical basis of the cuticles of plant nematodes (Blaxter and Robertson 1998). Both differences and similarities in structure and molecular architecture of the cuticle and in the basic molecular components, including structural proteins, cross-linking mechanisms, and remodeling systems, are likely between $C$. elegans and plant nematodes. Plant nematodes invade a host plant in the zone of root elongation at the $\mathrm{J} 2$ stage, migrate to the region in which protoxylem vessels are differentiating, and begin to induce feeding sites. For Meloidogyne spp., this process is accompanied by galling of the surrounding root tissue. The $\mathrm{J} 2$ stage feeds briefly from giant cells before rapidly undergoing a series of molts to form J3 and J4 that, rather atypically for plant nematodes, are nonfeed- 
ing stages. Finally the adult female is formed, which is again a feeding stage (Hussey and Grundler 1998). The essential nature of the extracellular matrix for nematode development makes processes involved with its synthesis and remodeling an excellent target for effective resistance strategies.

ECM proteins are highly cross-linked by disulphide and by di-, tri-, and isotrityrosine bonds. In C. elegans, two dual oxidase (duox) genes have been identified that are expressed in hypodermal cells and play a role in the formation of tyrosine cross-links in the ECM (Edens et al. 2001). The DUOX protein is a member of the NOX/DUOX family of NADPH oxidases that include the phagocyte gp91phox responsible for the generation of reactive oxygen species for bacteriocidal action (Lambeth 2002). These NOX-type proteins comprise a 6-transmembrane domain containing two haems and a cytosolic flavin domain containing a NADPH binding site. The DUOX proteins contain, in addition, a cytosolic two EF-hand calcium binding domain, an additional transmembrane-spanning helix, and an N-terminal extracellular peroxidase domain. It is proposed (Lambeth 2002) that superoxide generated by the NADPH oxidase activity would dismutate to hydrogen peroxide and react with the peroxidase domain to generate Compound I for use in oxidation of substrates such as tyrosine residues in extracellular structural proteins.

Here, we have used a similar juvenile "feeding" approach to that adopted by Urwin and associates (2002) for cyst nematodes to explore the functional consequences of RNA interference of a DUOX homolog in the root-knot nematode $M$. incognita. We show substantial phenotypic effects on nematode development up to 35 days after exposure to dsRNA.

\section{RESULTS}

\section{Dual oxidase genes and RNAi phenotype.}

The highly disruptive RNAi phenotype for duox in C. elegans led us to search for homologs in plant nematodes (Edens et al. 2001). Using a mixed N- and C-terminal probe from the $C$. elegans duoxl gene, we screened a $M$. incognita cDNA library and identified a clone with an insert of 723 bp that showed $65 \%$ nucleotide sequence identity to part of the $\mathrm{N}$-terminal peroxidase domain of duoxl. Subsequent polymerase chain reaction $(\mathrm{PCR})$ amplification from the cDNA library extended the length of sequence to $1,285 \mathrm{bp}$. The $67 \%$ amino acid sequence identity between $C$. elegans DUOX1 and the $M$. incognita DUOX homolog indicates this plant nematode sequence is part of a DUOX sequence rather than being derived from a simple haem peroxidase with which it shows only $30 \%$ identity (Fig. 1). Several residues have been identified from structural studies of animal peroxidases, such as human myeloperoxidase (Fiedler et al. 2000), as being involved in heme binding (Arg333, His336, Asp421, Arg424) and calcium binding (Asp96, Ser174, Phe170 peptidyl carbonyl, Thr168 and Asp172) and as a ligand pocket for $\mathrm{H}_{2} \mathrm{O}_{2}$ (His95 and Arg239), and many of these residues are conserved in the DUOX sequences (Fig. 1). Southern blot analysis has revealed the likely presence of three duox-related genes in M. incognita, and we have isolated a full-length cDNA clone and the corresponding genomic region for one of these from $M$. incognita. These data will be reported elsewhere.

\section{Plant infection assay with dsRNA treated $M$. incognita.}

We performed a series of RNAi experiments using a 629-bp portion of the peroxidase region of the $M$. incognita duox gene. As anticipated, there was no RNAi phenotype observed when $C$. elegans were fed with bacteria expressing this $M$. incognita duox-derived dsRNA, indicating that the 65\% nucleotide identity between the genes is insufficient to elicit an RNAi response. Experiments were then performed with $\mathrm{J} 2$-stage $M$. incognita placed in solutions containing various combinations of dsRNA, FITC, and $10 \mathrm{mM}$ octopamine and were incubated for $4 \mathrm{~h}$. FITC uptake was observed only in the presence of octopamine, with the majority of nematodes $(>95 \%)$ showing significant fluorescence often distributed along their length (Fig. 2A through C). This efficient dye uptake contrasts with the limited uptake observed for cyst nematodes (Urwin et al. 2002), suggesting that root-knot nematodes may provide a better target for routine RNAi studies. Effective uptake of dsRNA, by analogy with $C$. elegans, would be expected to elicit an efficient amplification response leading to systemic RNAi (Hannon 2002; Nishikura 2001; Sijen et al. 2001; Tijsterman et al. 2004; Zamore 2001). Two control treatments were normally used, a no-dsRNA treatment, which consisted of the standard feeding components without added dsRNA, and a $g f p$ dsRNA, to provide a nontarget sequence that was used at an equivalent concentration to the duox dsRNA.

Following dsRNA treatment, both standard reverse transcriptase (RT)-PCR and real-time RT-PCR were used to analyze the relative levels of duox transcript in control and dsRNA-treated samples. Figure 2D shows an example of a real-time experiment indicating that the level of mRNA was significantly reduced in duox-treated J2s compared with the no-dsRNA control and $g f p$ dsRNA-treated J2s (Fig. 2D).

Treated nematodes were also used to infect adzuki beans (Phaseolus angularis) in a soil-free pouch system (Atkinson and Harris 1989). This allows the level and synchrony of infection to be controlled and the infection sites to be easily monitored and subsequently dissected. Infection experiments were performed on separate occasions to collect five sets of data, three at 14 and two at 35 dpi.

At 14 days, the galls were counted to determine the level of infection. This was the same for no-dsRNA, $g f p$ dsRNA, and duox dsRNA treatments, indicating that the duox gene is not involved in the migration or infection processes. Roots were treated with acid fuchsin to stain the nematodes. In each experiment, the numbers of nematodes were counted at 14 days, and the nematodes were categorized based on size and shape.

Figure 3 shows data for experiment 1 comparing the size and shape of nematodes at $14 \mathrm{dpi}$, following treatment with no-dsRNA and with duox-dsRNA regimes. The normal expectation is that, by 14 days, the majority of nematodes will have developed as females with few fusiforms. The duox dsRNA treatment revealed fewer nematodes in the roots compared with the control, despite equivalent infection rates, and a greater proportion of fusiform stage with fewer females.

Fig. 1. ClustalW alignment of N-terminal peroxidase domains of invertebrate dual oxidase amino acid sequences with human heme peroxidases. CEDUOX1 and CEDUOX2, Caenorhabditis elegans DUOX1 (GenBank AAF71303) and DUOX2 (GenBank NP_490684), respectively, MI_DUOX, Meloidogyne incognita (GenBank DQ082753), ANOPH_DUOX, Anopheles gambiae (GenBank EAA13921), DROS_DUOX, Drosophila melanogaster (GenBank AAF51201), HUMAN_DUOX1, human duox 1 (GenBank NM_017434), HUMAN_MYELO, human myeloperoxidase (GenBank NM_000250) and HUMAN_LACTO, human lactoperoxidase (GenBank NM_00615). Residues conserved in all sequences are shown by a black diamond ( $\bullet$ ) below the residue, those implicated in heme interactions are highlighted in gray boxes, while those involved in calcium binding are indicated by an open circle (0) above. 
CEDUOX1

CEDUOX2

MI DUOX

ANOPH_DUOX

DROS DUOX

HUMAN DUOX 1

HUMAN_MYELO

HUMAN LACTO

CEDUOX1

CEDUOX 2

MI DUOX

ANŌPH DUOX

DROS DUOX

HUMAN DUOX1

HUMAN ${ }^{-}$MYELO

HUMAN_LACTO

CEDUOX 1

CEDUOX 2

MI DUOX

ANOPH DUOX

DROS DUOX

HUMAN DUOX1

HUMAN MYELO

HUMAN_LACTO

CEDUOX 1

CEDUOX 2

MI DUOX

ANOPH_DUOX

DROS DUOX

HUMAN DUOX1

HUMAN_MYELO

HUMAN LACTO

CEDUOX1

CEDUOX2

MI DUOX

ANOPH DUOX

DROS DUOX

HUMAN DUOX1

HUMAN ${ }^{-}$MYELO

HUMAN LACTO

CEDUOX 1

CEDUOX2

MI DUOX

ANOPH DUOX

DROS DUOX

HUMAN__DUOX1

HUMAN - MYELO

HUMAN_LACTO

CEDUOX1

CEDUOX2

MI DUOX

ANOPH DUOX

DROS DUOX

HUMAN DUOX1

HUMAN_MYELO

HUMAN_LACTO

CEDUOX 1

CEDUOX 2

MI DUOX

ANOPH DUOX

DROS DUOX

HUMAN DUOX1

HUMAN - MYELO

HUMAN_LACTO

CEDUOX1

CEDUOX 2

MI DUOX

ANOPH DUOX

DROS_DUOX

HUMAN DUOX1

HUMAN ${ }^{-}$MYELO

HUMAN_LACTO

MRSKHVLYIAILFSSIFGGKGIQQNEEFQRYDGWY MAAENFYNVNNFOSLPLEIKVOFSKETLFSALOOEAETORYDGWY YGGGY MSHVEKQRYDGWY MYSOTEKORYDGWY MGECLALAWTLLVGAWTPLGAONPISWEVOREDGWY CPEQDKYRTITGMC CDPCSPYRTITGDC

NNLANSEWGSAGSRLHRDARSYYSDGVYSVNN--------- SLPSARELSDILFKGE-S NNLANSEWGSAGSRLHRDARSYYSDGVYSVNN-------- - SLPSARELSDILFKGE-S NNFANPQLGSVRSRLHRDGASSYQDGVYRLDS----------SLPSARVISQLMFKGE-P NNLAHPDWGAVDNHLTRKAPSAYSDGVYVMAGS-- - - ---- NRPSPRKLSRLFMRGT $-D$ NNLAHPDWGSVDSHLVRKAPPSYSDGVYAMAGA-------- NRPSTRRLSRLFMRGK-D NNLMEHRWGSKGSRLQRLVPASYADGVYQPLGEP--------HLPNPRDLSNTISRGP-A NNRRSPTLGASNRAFVRWLPAEYEDGFSLPYGWTPGVKRNGFPVALARAVSNEIVRFPTD NNRRKPALGAANRALARWLPAEYEDGLSLPFGWTPGKTRNGFPLPLAREVSNKIVGYLNE $\rightarrow$

\section{$\odot$}

$\bullet \bullet$

GIPNTRGCTTLLAFFSQVVAHEIMQSNG--------VSCPLETLKIQVPLCDNVFDKECE GIPNTRGCTTLLAFFSQVVAYEIMQSNG--------VSCPLETLKIQVPLCDNVFDNECE GIPSRRNLTTMFAFFSOVIAYEIMQSTQ--------NSCPLEMHKI PVERCDPIFDKDCE GLPSMENRTALLAFFGOVVTNEIVMASE--------SGCPIEMHRIEIEKCDEMYDRECR GLGSKFNRTALLAFFGQLVANEIVMASE--------SGCPIEMHRIEIEKCDEMYDRECR GLASLRNRTVLGVFFGYHVLSDLVSVET--------PGCPAEFLNIRIPPGDPMFDPDQR QLTPDQERSLMFMOWGOLLDHDLDFTPEPAARASFVTGVNCETSCVQOPPCFPLKI PPND EGVLDQNRSLLFMQWGQIVDHDLDFAPDTELGSSEYSKAQCDEYCIQGDNCFPIMFPPND

\section{$\odot \odot \odot \bullet$}

GKT-----EIPFTRAKYDKATGNGLNSPREQINERTSWIDGSFIYGTTQPWVSSLRSFKQ GKT-----TIPFYRAKYDKATGNGLNSPREQINERTSWIDGSFIYGTTQPWVSALRSFKQ GKT-----DIPFTRAKYDKGTGHGLNSPREQINERTSWIDASFLYSTQEPWVAALRSFEN GDR-----YIPFHRAAY DRNTGQSPNAPREQINQMTAWI DGSFIYSTSEAWLNAMRSFQD GDK-----YIPFHRAAYDRDTGQSPNAPREQINQMTAWI DGSFIYSTSEAWLNAMRSFHN GDV $-----V L P F O R S R W D P E T G R S P S N P R D P A N O V T G W L D G S A I Y G S S H S W S D A L R S F S R$ PRIKNQADCI PFFRSCPACPGS--NITIRNQINALTSFVDASMVYGSEEPLARNLRNMSN PKAGTQGKCMPFFRAGFVCPTPPYKSLAREQINALTSFLDASFVYSSEPSLASRLRNLSS

GRLAEG-VPGYPPLNNPHIPLNN--PAPPQVHRLMSPDRLFMLGDSRVNENPGLLSFGLI GRLAEG-VPGYPPLNNPHIPLNN--PAPPQVHRLMSPDRLFMLGDSRVNENPGLLSFGLI GTLLEGPMPGYPSFNDPHIPLIN--PPPPQI HRLMNPERLFILGDPRINENPGLLSFGLI GALLTDKQGTMPVKNTMRVPLFN--NPVPHVMRMLSPERLYLLGDPRTNQNPALLSFAIL GTLLTEKDGKLPVRNTMRVPLFN--NPVPSVMKMLSPERLFLLGDPRTNONPAILSFAIL GQLASGPDPAFPRDSQNPLLMWA--APDPATGQNG-PRGLYAFGAERGNREPFLQALGLL QLGLLAVNQRFQDNGRALLPFDNLHDDPCLLTNRSARI PCFLAGDTRSSEMPELTSMHTL PLGLMAVNQEVSDHGLPYLPYDSKKPSPCEFINTTARVPCFLAGDSRASEHILLATSHTL $\bullet-$

LERWHNYNANQI HREHPDWTDEQIFQAARRLVIASMQKI IAYDFVPGLLGEDVR---LSN LFRWHNYNANQIYREHPDWTDEQIFQAARRLVIASMQKI IAYDFVPGLLGEDVR---LSN LFRWHNIQALRLQQEFPEWT DEELFQGARRLVIATLQS IVLYEFLPVLLS ISKEE--IPE FLRWHNVVAKRVRRQHRDWSDEEIFORARRVVIASLONIVAYEYLPAFLDKEI P---- FLRWHNTLAQRIKRVHPDWSDEDIYQRARHTVIASLQNVIVYEYLPAFLGTSLP--- - P WFRYHNLWAQRLARQHPDWEDEELFQHARKRVIATYQNIAVYEWLPSFLQKTLP-----E LLREHNRLATELKSLNPRWDGERLYQEARKIVGAMVQI ITYRDYLPLVLGPTAMRKYLPT FLREHNRLARELKRLNPQWDGEKLYOEARKI LGAFVQI ITFRDYLPI LLG-DHMOKWIPP

YTKYMPHVPPGISHAFGAAAFRFPHSIVPPAMLLRKRGNKCEFR----TEVGGYPALRLC YTKYMPHVPPGISHAFGAAAFRFPHSIVPPAMLLRKRGNKCEFR--- TEVGGYPALRLC YQGYNPHVPPGISHSFATTAFRFPHTLVPPALLLRKRNGNCEFR----KEVGGFPALRLC YDGYKADTHPGVSHMFQAAAFRFGHSLI P PGLFR--RDGQCNFR----RTNMDFPALRLC YEGYKQDIHPGIGHIFQAAAFRFGHTMI P PGIYR--RDGQCNFK----ETPMGYPAVRLC YTGYRPFLDPSISSEFVAASEQFLSTMVP PGVYMR--NASCHFQGVINRNSSVSRALRVC YRSYNDSVDPRIANVFT-NAFRYGHTLIQPFMFRLDNRYQPMEP-------- NPRVPLS YQGYSESVDPRISNVFT-FAFRFGHLEVPSSMFRLDENYQPWGP---------EPELPLH

ONWWNAQD--IVKEYSVDEIILGMASQIA--ERDDNIVVEDLRDYIFGPMHFSR-LDVVA ONWWNAOD--IVKEYSVDEII LGMASOIA--ERDDNIVVEDLRDYIFGPMHFSR-LDVVA QNWWNAQD--IVREYSVDEIVLGMASQIA--EDEDHIVVEDLRDFIFGPMHFTR-LDVVS STWWNSND--VLDNT PVEEFIMGMASQIA--EKEDPLLCSDVRDKLFGPMEFTR-RDLGA STWWDSSG--FFADTSVEEVLMGLASQIS--EREDPVLCSDVRDKLFGPMEFTR-RDLGA NSYWSREHPSLQSAEDVDALLLGMASQIA--EREDHVLVEDVRDFWPGPLKFSR-TDHLA RVFFASWR--VVLEGGIDPILRGLMATPAKLNRQNQIAVDEIRERLFEQVMRIG-LDLPA TLFFNTWR--MVKDGGI DPLVRGLLAKKSKLMKQNKMMTGELRNKLFQPTHRI HGFDLAA

SSIMRGRDNGVPPYNELRRTEGLAP-KTWETMNEDFYKKHTAKVEKLKELYGGNILYLDA SSIMRGRDNGVPPYNELRRTFGLAP-KTWETMNEDFYKKHTAKVEKLKELYGGNI---- TSIMRARDNGLPGYNQLRKAYKLKP-NDWTTINPKLNETNP-----------------LNIMRGRDNGLPDYNTARAAYRLPKKKSWRDINPAVFERQPELLDLLIKTYDNQLDNVDV LNIMRGRDNGLPDYNTARESYGLKRHKTWTDINPPLEETQPELLDMLKEAYDNKLDDVDV SCLQRGRDLGLPSYTKARAALGLSPITRWQDINPALSRSNDTVLEATAALYNQDLSWLEL LNMQRSRDHGLPGYNAWRRFCGLPQPETVGQLGTVLRNLKLARKLMEQYGTPNNIDIWMG INTQRCRDHGQPGYNSWRAFCDLSQPQTLEELNTVLKSKMLAKKLLGLYGTPDNIDIWIG 
Image analysis was used to measure roundness ( $\mathrm{R})$, area (A), and length (L) for 55 randomly dissected nematodes from each treatment at 14 days. We have previously shown that the ratio of roundness to length allows classification of $M$. incognita into three morphological classes, fusiform $(\mathrm{J} 2, \mathrm{~J} 3, \mathrm{~J} 4$, male), saccate females, and gravid females (Atkinson et al. 1996). Such measurements provide information on the relative growth rates and stages of development of nematodes within the population. Filter values for $\mathrm{R}$ and $\mathrm{L}$ of $M$. incognita individuals can be applied to separate the population into three classes: fusiform ( $\mathrm{J} 2, \mathrm{~J} 3, \mathrm{~J} 4$, and male), $\mathrm{R}>3.06$ and $\mathrm{L}<422$ $\mu \mathrm{m}$; saccate (young female), $\mathrm{R}<3.06$ and $\mathrm{L}<422 \mu \mathrm{m}$; enlarged saccate (gravid female), $\mathrm{R}<3.06$ and $\mathrm{L}>422 \mu \mathrm{m}$ (Atkinson et al. 1996). Data for 55 individuals from both con-
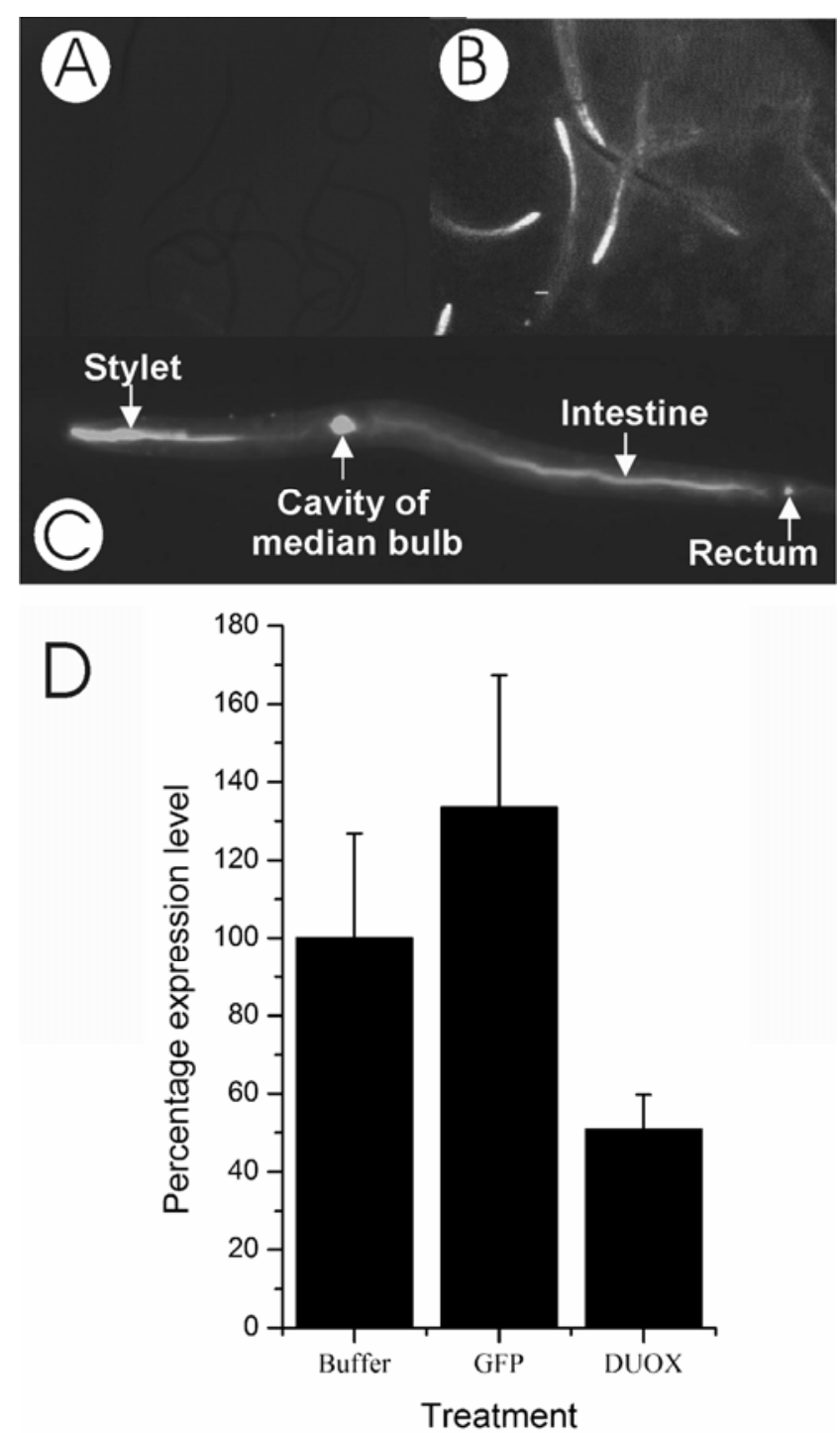

Fig. 2. RNAi uptake by nonfeeding Meloidogyne incognita J2s. fluorescein isothiocyanate (FITC) was used to report uptake of material from the incubating solution. A, No FITC uptake is observed in the absence of octopamine. B, In the presence of $10 \mathrm{mM}$ octopamine, efficient uptake of FITC is observed. C, In some cases, very extensive FITC fluorescence is observable throughout the nematode digestive and excretory system. D, Real-time polymerase chain reaction analysis of the duox peroxidase following RNAi treatment of $M$. incognita. J2 nematodes were soaked in buffer plus octopamine (control), buffer plus octopamine supplemented with $2 \mu \mathrm{g}$ of ds $g f p$ RNA (GFP) per microliter, or buffer plus octopamine supplemented with $2 \mu \mathrm{g}$ of dsMiduox RNA (DUOX) permicroliter, showing reduced expression in dsMiduox-treated $\mathrm{J} 2$ nematodes compared with both control treatments. trol-treated and duox dsRNA-treated nematodes are shown in Figure 3. The number of fusiform and saccate females are significantly higher for the $d u o x$ dsRNA-treated population $(n=$ 12 and 25, respectively) than for the no-dsRNA control ( $n=3$ and 14, respectively), while the number of enlarged females is significantly greater in the control $(n=38)$ than in the dsRNAtreated population $(n=18)$. Chi square analysis reveals a highly significant difference in proportions of the three categories of nematodes between the two treatments $(P<0.001)$.

These results suggest a substantial effect of duox dsRNA on the number and development of $M$. incognita at $14 \mathrm{dpi}$. In order to confirm this observation and to ensure that the effect was not the result of a nonspecific dsRNA effect, further experiments were performed that included a $g f p$ dsRNA control. Comparison of the no-dsRNA and $g f \mathrm{p}$ dsRNA treatment in these experiments revealed no significant difference, indicating that $g f p$ dsRNA was not affecting nematode numbers or developmental progress. In two further independent experiments, the ability of $M$. incognita to complete molts and reach the saccate stage by 14 dpi following RNAi treatment were examined, as shown in Figure 4. In experiment 2, the mean number of nematodes per plant for 10 root systems examined was similar for both duox and a gfp dsRNA treatment. However, the developmental stage reached by these nematodes was different, with a significantly lower number of saccate females and a greater number of fusiforms after duox dsRNA treatment compared with the $g f p$ dsRNA treatment (Fig. 4). In experiment 3, the mean number of nematodes per plant was significantly lower in the duox dsRNA treatment ( $t$ test; $P<0.05$ ) and, in addition, there was a statistically significant reduction in the proportion of saccate females. These findings support the observations of experiment 1 .

\section{Longer-term developmental consequences of RNAi treatment of $M$. incognita.}

To examine the effects of duox dsRNA treatment on fecundity, experiments were performed to measure nematode numbers following acid fuchsin staining and to count the number of eggs produced at $35 \mathrm{dpi}$ (Fig. 5). In experiment 4 at $35 \mathrm{dpi}$, the number of nematodes in roots treated with duox dsRNA was 126, compared with control treatment (no dsRNA) of 312 . There was also a substantial difference in the average number of eggs per female between the two treatments $(514 \pm 48$ and $676 \pm 50$, respectively). The effect on the fecundity of egg-laying females at 35 dpi was examined in a further experiment (experiment 5). Eggs were collected from individual root masses from 10 fecund females on the root surface at $35 \mathrm{dpi}$. Again, fewer eggs were recovered from egg masses following duox dsRNA treatment compared with $g f p$ dsRNA treatment (239 \pm 23 and $388 \pm 27$, respectively) (Fig. 5). Egg number provides an important measure of reproductive success. So, for example, in experiment 4, the lower number of eggs per female in the duox dsRNA-treated population, coupled with the reduced number of females, represents substantial reduction in eggs produced $(64,764)$ compared with the no-dsRNA control $(210,912)$.

\section{DISCUSSION}

This study demonstrates a reproducible consequence on the nematode number and developmental stage reached by $M$. incognita following treatment with a dsRNA from the peroxidase-encoding domain of a dual oxidase gene. The molecular consequences on the nematode of interfering with duox expression remain to be determined. Evidence from $C$. elegans suggests the effect is likely to be on normal cuticle biosynthesis. Duox RNAi effects on C. elegans yield phenotypes compa- 
rable to genetic defects of collagen and cuticle biosynthesis. Morphological and biochemical studies comparing wild type and duox RNAi C. elegans were consistent with a role for DUOX in cuticle biosynthesis (Edens et al. 2001), a process that is extremely important in root-knot nematodes, not only preceding each molt but also to allow the rapid expansion of the female body critical for reproductive success. There are, however, significant morphological differences in the ECM architecture between $C$. elegans and $M$. incognita. Further analyses are required to investigate the molecular basis for the pronounced RNAi effect observed in this study on $M$. incognita development.

The ability to identify changes in transcript levels following dsRNA incubations is highly variable, and one must question the validity of using this approach for RNAi studies of plant nematodes. We could demonstrate a reduction in transcript within separate treated populations of duox dsRNA-treated nematodes by both semiquantitative PCR and by real time PCR analysis. However, in other cases, we were unable to detect transcript even in untreated populations. Successful detection of transcripts will depend upon the magnitude of expression and the temporal and spatial expression pattern during development. In $C$. elegans, it has been shown that duox is expressed in a cyclic manner, and thus, the time at which the sample is taken for RNA preparation would have a significant impact on the ability to detect transcript. It is clear that RNAi effects can be observed many days after the initial treatment, which implies retention of dsRNA or products that are activated upon expression of the target gene. For genes expressed only following plant infection, those expressed in a temporally and spatially restricted manner or at very low levels, the feasibility of undertaking meaningful real-time analysis is technically extremely difficult and may be impossible. Commonly for C. elegans RNAi studies, there is no routine use of transcript determination but rather a reliance upon detection of a phenotype in the target treatment compared with controls (Ashrafi et al. 2003; Kamath et al. 2003). The observation of a phenotype is taken as evidence for an RNAi effect upon the target gene, although it is recognized that the phenotype may result from an indirect effect of knocking out the target gene. Given the relative simplicity of $C$. elegans compared with the complexity of the biotrophic nature of plant nematode interactions with their host, we suggest that a similar phenotypic approach to demonstrating RNAi effects should be considered appropriate for plant nematodes.

Our bioassay data at 14 dpi shows two effects: first, a reduction in the number of nematodes developing on the plant, and second, a reduction in the rate of development of the nematodes. The reduced number of nematodes could be due to premature death resulting from failure to develop or to an increase in the number of males that then leave the root, although as

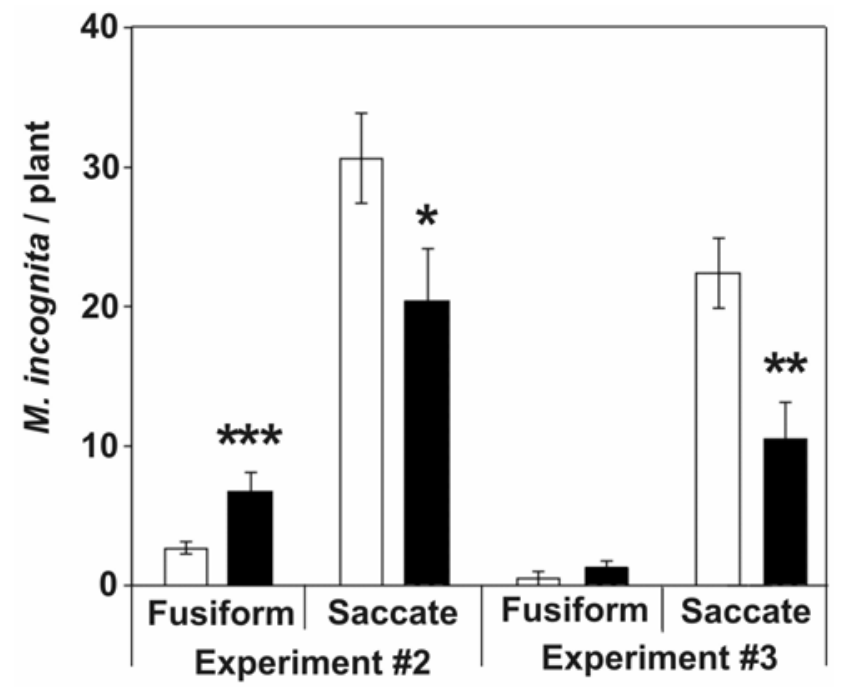

Fig. 4. Number of fusiform and saccate individuals of Meloidogyne incognita per plant at 14 dpi after treatment with dsRNA targeted at green fluorescent protein control (white bars) and dual oxidase (black bars). Values for the two experiments ( 2 and 3 ) are means \pm standard error of the mean, with those for duox compared with corresponding control values, $(P<$ $0.05, * ; P<0.01, * * ; P<0.001, * * *)$. Statistical comparison is based on comparison of marginal means using univariate analysis of variance.

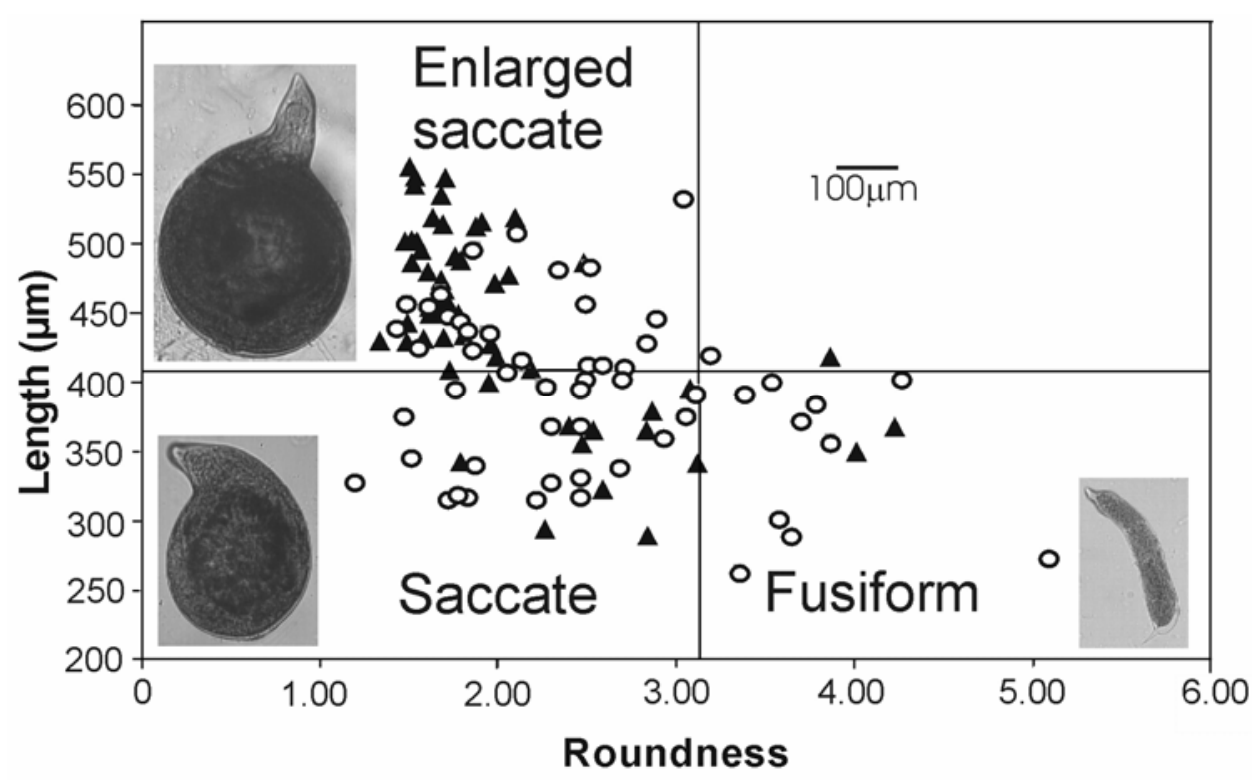

Fig. 3. Plot showing size and stage of development of Meloidogyne incognita. The length and roundness filters, indicated by the horizontal and vertical lines, allow assignment of individual nematodes within three classes, fusiform (lower right quadrant), saccate female (lower left quadrant), and enlarged saccate female (upper left quadrant). For the control treatment, 55 individuals were measured and are represented by a black triangle ( $\mathbf{\Delta}$ ); similarly, 55 individuals from the RNAi treatment were measured and are represented by an open circle $(\mathrm{O})$. Representative nematodes are also shown to scale, indicating the difference in shape and size of the three classes. 
observed for cyst nematodes (Urwin et al. 2002), males should still be present at $14 \mathrm{dpi}$. While the uptake of dsRNA by $M$. incognita is efficient, with around $95 \%$ of juveniles displaying oral ingestion, there remains a population that is unlikely to be affected and which will therefore develop normally, leading to a background of normal females. We have not taken steps to exclude these nematodes from this analysis. In addition, there may be variability in the level of dsRNA uptake by nematodes within a single experiment and between experiments. It is likely that a threshold level of uptake is required to arrest development sufficiently to prevent further development thus leading to death. However, for the remainder of the population ingesting lower levels of dsRNA, there may be a transient effect of RNAi. Such nematodes may subsequently resume their developmental program and produce the same number of eggs as seen for the control treatment, but they would be significantly delayed compared with the control nematodes and thus, by $35 \mathrm{dpi}$, would be smaller and have produced fewer eggs. These features may be responsible for the limited variability observed between experiments. However, we observed a common trend of a reduction in the number of nematodes within the root and a decrease in the number of females that formed by $14 \mathrm{dpi}$. This trend continued to $35 \mathrm{dpi}$ when the reproductive capacity of the females was compromised, as demonstrated by reduction in the number of eggs per female. Coupled with the reduced numbers of females, this lower egg production leads to a significant 50 to $70 \%$ reduction in the total number of eggs produced. This result can be compared with a level of $70 \%$ field resistance (Urwin et al. 2001) achieved by transgenic expression of phytocystatins within plant roots to disrupt nematode feeding. The duox RNAi effect reported here is potentially much more dramatic than this transgenic resistance effect, as it arises from a single 4-h preinfection treatment with dsRNA and, yet, it elicits a response that has measurable consequences 35 days later. If it were possible to achieve exposure of nematodes to appropriate dsRNA molecules during feeding from the plant, one could expect a substantial and prolonged inhibition of nematode development leading potentially to full resistance.

This study has demonstrated an important application of RNAi technology as a bioassay for the identification of rootknot nematode targets of potential value in the development of resistance in transgenic plants or in the search for new biologically based nematicides for agricultural use. The work indicates that dsRNA is more efficiently taken up by root-knot

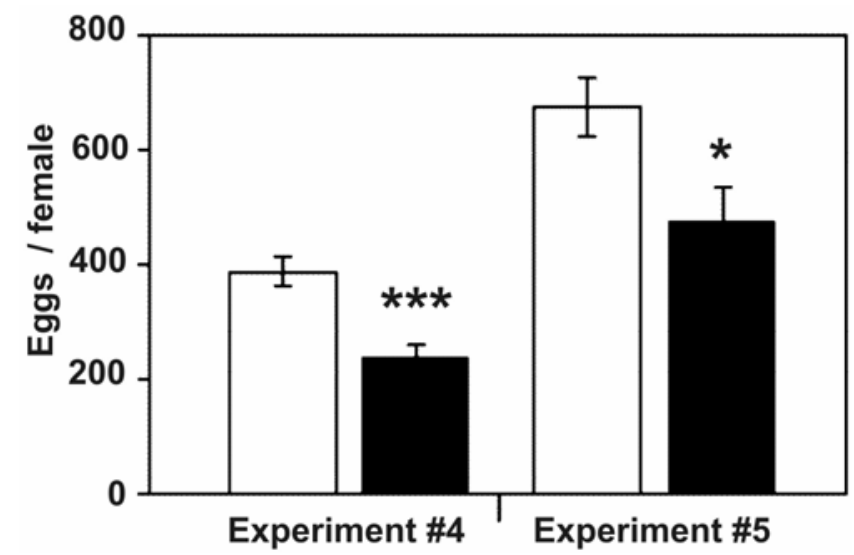

Fig. 5. Number of eggs of Meloidogyne incognita per plant recovered after $35 \mathrm{dpi}$ after treatment with dsRNA targeted at green fluorescent protein (GFP) control (white bars) and dual oxidase (black bars). Values for two experiments are means \pm standard error of the mean, with those for duox compared with corresponding GFP values, $(P<0.05$, *; $P<0.001$, ***; student $t$-test). nematodes than cyst nematodes, avoiding the need to perform FITC-based selection for affected nematodes prior to analysis. Our results demonstrate the importance of a duox gene in $M$. incognita, probably related to ECM development, and identifies such genes as potential targets for new transgenic resistance strategies.

The use of highly selective dsRNA molecules targeted at nematode ECM processes without production of foreign proteins may prove more acceptable to critics of genetic modification approaches to pest control. It will be important to investigate the potential for delivery of dsRNA molecules from plant cells to feeding nematodes. Plants display post-transcriptional gene silencing that operates in the same manner as RNAi in nematodes, with the dsRNA degraded to siRNAs of around 21 nucleotides (Agrawal et al. 2003; Hamilton and Baulcombe 1999). Plant constructs have been generated to allow expression of dsRNA molecules to silence genes within plants, to explore gene function (Wesley et al. 2001). Control of nematodes presents additional challenges, as it may require stable production in the plant cell of dsRNAs that are not degraded by the plant but remain sufficiently long, such that, when ingested up by the nematode, they can be processed to elicit an RNAi response.

\section{MATERIALS AND METHODS}

\section{cDNA library screening.}

A cDNA library of young feeding females of $M$. incognita was provided by J. Shingles (University of Leeds). Approximately 200,000 plaques were screened in duplicate with ${ }^{32} \mathrm{P}$ dCTP-labeled (Prime it II random primer labeling kit, Stratagene, La Jolla, CA, U.S.A.) probe comprising the C. elegans duox PCR fragments described above. Following hybridization for $16 \mathrm{~h}$ at $55^{\circ} \mathrm{C}$ in $6 \times \mathrm{SSC}(1 \times \mathrm{SSC}$ is $0.15 \mathrm{M} \mathrm{NaCl}$ plus $0.015 \mathrm{M}$ sodium citrate), $5 \times$ Denhardt's solution, and $0.5 \%$ sodium dodecyl sulfate (SDS), $100 \mu \mathrm{g}$ of denatured salmon sperm DNA per $\mathrm{ml}$ and after two washes at $55^{\circ} \mathrm{C}$ in $2 \times \mathrm{SSC}$ containing $0.1 \%$ SDS for $30 \mathrm{~min}$., the filters were exposed to autoradiography film (Fuji Super RX film, Fuji, Tokyo) at $80^{\circ} \mathrm{C}$. Secondary and tertiary screenings were performed under identical conditions. Plaques were subjected to recombinant pBluescript rescue according to manufacturer's instructions (Stratagene).

\section{Preparation of dsRNA}

of a $M$. incognita putative duox gene.

The cDNA insert from a hybridizing clone, designated pMiDuox1, was sequenced using an ABI373XL instrument (Applied Biosystems, Foster City, CA, U.S.A.), and the coding region (GenBank accession number DQ082753) was translated and used to perform a PSI-BLAST search. Protein sequence alignments were performed using CLUSTALW. A HindIII site $95 \mathrm{bp}$ from the $5^{\prime}$ end and an XhoI site at the $3^{\prime}$ end were used to clone a 629-bp fragment into pPD129.36, to give pMiDuox1, which was transformed into HT115 cells for use in C. elegans feeding experiments. For $M$. incognita feeding experiments, pMiDuox1 was linearized using XhoI and XbaI and was transcribed in vitro (Ampliscribe T7 high yield transcription kit, Cambio, Cambridge) according to manufacturer's instructions. Sense and antisense transcripts were then annealed for $30 \mathrm{~min}$ at $37^{\circ} \mathrm{C}$ and were analyzed by agarose gel electrophoresis.

\section{RNAi treatment of $M$. incognita.}

The RNAi soaking method was performed essentially according to Urwin and associates (2002). Briefly, root galls from infected tomato plants at 8 weeks postinfection were 
washed thoroughly under running tap water. The washed roots were chopped into small pieces ( 3 to $4 \mathrm{~cm}$ ) and were placed on paper tissue supported on a coarse sieve $(250 \mu \mathrm{m})$. The sieve was placed inside a funnel over a $50-\mathrm{ml}$ Falcon tube. The funnel was kept under a fine mist of water $\left(25^{\circ} \mathrm{C}\right)$, sprayed continuously from mist nozzles. The hatched nematodes were collected in a $50-\mathrm{ml}$ Falcon tube every $24 \mathrm{~h}$ for 4 days. Approximately $15,000 \mathrm{~J} 2 \mathrm{~s}$ were soaked in soaking buffer (10 mM octopamine in M9 salts [Sigma, Poole, Dorset, U.K.], $1 \mathrm{mg}$ of FITC in $1 \mathrm{ml}$ of dimethyl formamide, dsRNA at $2 \mu \mathrm{g} / \mu \mathrm{l}$ ) for $4 \mathrm{~h}$ at room temperature, with occasional flicking in a $1.5-\mathrm{ml}$ microcentrifuge tube. Controls consisting of soaking buffer plus octopamine only were used in experiments 1 and 4, while in the remainder of experiments, this control was used together with an additional control of soaking buffer plus $g f p$ dsRNA and octopamine, as a nonspecific dsRNA control. FITC uptake was analyzed using a Zeiss axiovert 135-inverted microscope (Carl Zeiss Ltd., Hertfordshire, U.K.) with Improvision imaging software (Improvision Ltd., Coventry, U.K.) and a monochromator light source using a 520-nm filter. A proportion of $g f p$ or duox dsRNA-treated and control no dsRNA-treated nematodes were used for semiquantitative PCR analysis. Statistical analysis was carried out using a package for a personal computer (SPSS release 11 for Windows [SPSS Inc. Chicago]).

\section{RNA isolation and real-time PCR.}

Real-time PCR was used to assess the level of endogenous dual oxidase in the nematodes following the different treatments (Miduox dsRNA, gfp dsRNA, and no dsRNA). RNA was extracted according to the manufacturer's instructions, using the RNeasy plant minikit (Qiagen, Courtaboeuf, France) and DNase-treated on the column, using the RNase-Free DNase Set 50 (Qiagen). For each treatment, 20- $\mu$ l reverse transcripttion reactions were set up with duplicate samples of $200 \mathrm{ng}$ of RNA, using Superscript II reverse transcriptase (Stratagene) according to the manufacturer's instructions, with the exception that a cocktail of random hexamers and anchored oligodT $\mathrm{T}_{15}$ primers were used at a final concentration of $6.25 \mu \mathrm{M}$.

A 5- $\mu$ l aliquot was removed from each cDNA preparation, was pooled and diluted to $300 \mu \mathrm{l}$ with sterile distilled water, and was used to make threefold serial dilutions from 1 to $81 \times$ to generate a standard curve. Standard PCR samples were performed in duplicate. To each of the remaining $15-\mu \mathrm{l}$ samples of cDNA, aliquots of $585 \mu \mathrm{l}$ of water were added. A 5- $\mu \mathrm{l}$ aliquot of each sample was then used for PCR. For each cDNA sample, PCR was performed in triplicate, using the primer pairs duoxF1 5'- ACA AAA CAG TTG CCC TTT GG 3' and duoxR1 5'ATC CAT GTC CAG TCC CTT TG-3' or ef- $1 \alpha$ F 5'- GGA AAA GAA AAG ATC CAT ATC AAC ATT-3' and ef- $1 \alpha \mathrm{F} 5^{\prime}-$ TGC CCA GTG TTG TGG ATT T-3' to amplify a duox region and a control region of the coding region of elongation factor $1 \alpha$. Real-time PCR was carried out on a BioRad ICycler (BioRad, Hercules, CA, U.S.A.) with the following cycling conditions: $95^{\circ} \mathrm{C} \times 3 \mathrm{~min}(1$ cycle to activate the polymerase enzyme), $95^{\circ} \mathrm{C} \times 15 \mathrm{~s}, 60^{\circ} \mathrm{C} \times 30 \mathrm{~s}$ ( 40 cycles). Initial data analysis was carried out by the ICycler software, which created threshold cycle values $(\mathrm{Ct})$ and extrapolated relative levels of PCR product from the standard curve. These relative values were then converted to true relative levels by dividing the expression level of dual oxidase by the expression level of the control gene $E F-1 \alpha$ (accession number BI 773515).

\section{Infection of plants in pouches.}

Phaseolus angularis (adzuki bean) plants were grown in CYG seed growth pouches (Mega International, Minneapolis) and were infected with $\mathrm{J} 2 \mathrm{~s}$ as described (Atkinson and Harris 1989). Infection points ( 3 to 4 per pouch) were each infected with 15 nematodes. Plants were infected with nematodes treated with soaking buffer containing pMiDuox1-derived dsRNA, GFP-derived dsRNA, or without dsRNA. The pouches were placed 10 to a tray spaced $15 \mathrm{~mm}$ apart, were immersed in $1 \mathrm{~cm}$ of water, and were grown in a glasshouse at $30^{\circ} \mathrm{C}$ and 56 to $60 \%$ humidity for 14 or 35 days.

\section{Staining of nematodes in plant roots and image analysis.}

The infected roots were collected from the pouches after 14 or $35 \mathrm{dpi}$ and were soaked in $1 \%$ bleach for 2 min to clear and permeabilize. After rinsing in water, they were boiled in acid fuchsin (350-mg stain in 1 liter of $25 \%$ acetic acid) for $2 \mathrm{~min}$, were rinsed in water, and were transferred to the acidified glycerol for examination and dissection (Atkinson et al. 1996). Nematodes were dissected from the roots of infected plants by separating them in a $60-\mathrm{mm}$ petri dish in acidified glycerol. They were picked at random and were dissected out by tearing the root tissue gently, using $0.6-\mathrm{mm}$ needles. The dissected nematodes were mounted on the glass slide in a drop of acidified glycerol, and the measurement of length, area, and roundness was carried out using the Image analysis tool kit from LEICA QWin under a Leitz (DMBR) Leica microscope (Bensheim, Germany) attached to a color camera (Kappa F15MCC). At 35 days, mature females were picked from the roots using flat bladed tweezers, and care was taken to ensure egg masses remained intact. Using needles, the gelatinous matrix was separated around the eggs, and the eggs from randomly picked mature females were counted on a glass slide. Eggs from 10 females from each treatment were counted, and the mean egg number was multiplied by the total number of females to estimate the total egg count from infected roots.

\section{ACKNOWLEDGMENTS}

We thank J. Shingles and C. Lilley for access to cDNA libraries and P. Urwin and other members of the Leeds Nematode Laboratory for advice. M Bakhetia is grateful for financial support from a U.K. Overseas Research Studentship award, a University of Leeds Tetley and Lupton award, and the British Federation of Women Graduates. This work was supported by the Biotechnology and Biological Sciences Research Council.

\section{LITERATURE CITED}

Agrawal, N., Dasaradhi, P. V. N., Mohmmed, A., Malhorta, P., Bhatnagar, R. K., and Mukherjee, S. K. 2003. RNA interference: Biology, mechanism, and applications. Microbiol. Mol. Biol. Rev. 64:657-685.

Ashrafi, K., Chang, F. Y., Watts, J. L., Fraser, A. G, Kamath, R. S., Ahringer, J., and Ruvkun, G. 2003. Genome-wide RNAi analysis of Caenhorhabditis elegans fat regulatory genes. Nature 421:268-272.

Atkinson, H. J., and Harris, P. D. 1989. Changes in nematode antigens recognized by monoclonal antibodies during early infections of soya beans with the cyst nematode Heterodera glycines. Parasitology 98:479-487.

Atkinson, H. J., Urwin, P. E., Clarke, M. C., and McPherson, M. J. 1996. Image analysis of the growth of Globodera pallida and Meloidogyne incognita on transgenic tomato roots expressing cystatins. J. Nematol. 28:209-215.

Atkinson, H. J., Urwin, P. E. and McPherson, M. J. 2003. Engineering plants for nematode resistance. Ann. Rev. Phytopathol. 41:615-639

Blaxter, M. L., and Robertson, W. M. 1998. The cuticle. Pages 25-48 in: The Physiology and Biochemistry of Free-Living and Plant-Parasitic Nematode. R. N. Perry and D. J. Wright, eds. CABI Publishing, Oxon, U.K.

Chitwood D. J. 2003. Research on plant-parasitic nematode biology conducted by the United States Department of Agriculture-Agricultural Research Service. Pest Manag. Sci. 59:748-53.

Edens, W. A., Sharling, L., Cheng, G. J., Shapira, R., Kinkade, J. M., Lee, T., Edens, H. A., Tang, X. X., Sullards, C., Flaherty, D. B., Benian, G. M., and Lambeth, J. D. 2001. Tyrosine cross-linking of extracellular matrix is catalyzed by Duox, a multidomain oxidase/peroxidase with homology to the phagocyte oxidase subunit gp91 phox. J. Cell Biol. 154:879-891.

Fanelli, E., Di Vito, M., Jones, J. T., and De Giorgi, C. 2005. Analysis of 
chitin synthase function in a plant parasitic nematode, Meloidogyne artiellia, using RNAi. Gene 349:87-95

Fiedler, T. J., Davey, C. A., and Fenna, R. E. 2000. X-ray crystal structure and characterization of halide-binding sites of human myeloperoxidase at 1.8̊̊ resolution. J. Biol. Chem. 275:11964-71.

Fire, A., Xu, S. Q., Montgomery, M. K., Kostas, S. A., Driver, S. E., and Mello, C. C. 1998. Potent and specific genetic interference by doublestranded RNA in Caenorhabditis elegans. Nature 391:806-811.

Fridkin, A., Mills, E., Margalit, A., Newfeld, E., Lee, K. K., Feinstein, N., Cohen, M., Wilson, K. L., and Gruenbaum, Y. 2004. Matefin, a Caenorhabditis elegans germ line-specific SUN-domain nuclear membrane protein, is essential for early embryonic and germ cell development. Proc. Natl. Acad. Sciences U.S.A. 101:6987-6992.

Hamilton, A. J., and Baulcombe, D. C. 1999. A species of small antisense RNA in posttranscriptional gene silencing in plants. Science 286:950952

Hannon, G. J. 2002. RNA interference. Nature 418:244-251.

Hussey, R. S., and Grundler, F. M. W. 1998. Nematode parasitism of plants. Pages 213-243 in: The Physiology and Biochemistry of FreeLiving and Plant-Parasitic Nematodes. R. N. Perry and D. J. Wright, eds. CABI Publishing, Oxon, U.K.

Johnstone, I. L. 2000. Cuticle collagen genes. Trends Genet. 16:21-27.

Kamath, R. S., Fraser, A. G., Dong, Y., Poulin, G., Durbin, R., Gotta, M., Kanapin, A., Le Bot, N., Moreno, S., Sohrmann, M., Welchman, D. P., Zipperlen, P., and Ahringer, J. 2003. Systematic functional analysis of the Caenhorhabditis elegans genome using RNAi. Nature 421:231-237.

Lambeth, J. D. 2002. Nox/Duox family of nicotinamide adenine dinucleotide (phosphate) oxidases. Curr. Opin. Hematol. 9:11-17.

Lilley, C. J., Devlin, F., Urwin, P. E., and Atkinson, H. J. 1999. Parasitic nematodes, proteinases and transgenic plants. Parasitol. Today 15:414417.

Maeda, I., Kohara, Y., Yamamoto, M., and Sugimoto, A. 2001. Large-scale analysis of gene function in Caenorhabditis elegans by high-throughput RNAi. Current Biology 11:171-176.

McPherson, M. J., Urwin, P. E., Lilley, C. J., and Atkinson, H. J. 1997. Engineering plant nematode resistance by an anti-feedant approach. Pages 237-249 in: Cellular and Molecular Basis for Plant-Nematode Interactions. C. Fenoll, S. Ohl, and F. Grundler, eds. Kluwer, Dordrecht, The Netherlands.
Nishikura, K. 2001. A short primer on RNAi: RNA-directed RNA polymerase acts as a key catalyst. Cell 107:415-418.

Riddle, D. L., Blumenthal, T., Meyer, B. J., and Priess, J. R., eds. 1997. C. elegans II. Cold Spring Harbor Laboratory, Cold Spring Harbor, NY, U.S.A.

Sijen, T., Fleenor, J., Simmer, F., Thijssen, K. L., Parrish, S., Timmons, L. Plasterk, R. H. A., and Fire, A. 2001. On the role of RNA amplification in dsRNA-triggered gene silencing. Cell 107:465-476.

Tabara, H., Grishok, A., and Mello, C. C. 1998. RNAi in C. elegans: Soaking in the genome sequence. Science 282:430-431.

Tijsterman, M., May, R. C., Simmer, F., Okihara, K. L., and Plasterk, R. H. 2004. Genes required for systemic RNA interference in Caenorhadbitis elegans. Curr. Biol. 14:111-116.

Timmons, L., Court, D. L., and Fire, A. 2001. Ingestion of bacterially expressed dsRNAs can produce specific and potent genetic interference in Caenorhabditis elegans. Gene 263:103-112.

Timmons, L., Tabara, H., Mello, C. C., and Fire, A. Z. 2003. Inducible systemic RNA silencing in Caenorhabditis elegans. Mol. Biol. Cell 14:2972-2983

Urwin, P. E., Atkinson, H. J., Waller, D. A., and McPherson, M. J. 1995. Engineered oryza cystatin-I expressed in transgenic hairy roots confers resistance to Globodera pallida. Plant J. 8:121-131.

Urwin, P. E., Troth, K. M., Zubko, E. I., and Atkinson, H. J. 2001. Effective transgenic resistance to Globodera pallida in potato field trials. Mol. Breeding 8:95-101.

Urwin, P. E., Lilley, C. J., and Atkinson, H. J. 2002. Ingestion of doublestranded RNA by pre-parasitic juvenile cyst nematodes leads to RNA interference. Mol. Plant-Microbe Interact. 15:747-752.

Wang, T. Y., Deom, C. M., and Hussey, R. S. 1998. Identification of a Meloidogyne incognita cuticle collages gene and characterization of the developmental expression of three collagen genes in parasitic stages. Mol. Biochem. Parasitol. 93:131-134.

Wesley, S. V., Helliwell, C. A., Smith, N. A., Wang, M. B., Rouse, D. T., Liu, Q., Gooding, P. S., Singh, S. P., Abbott, D., Stoutjesdijk, P. A., Robinson, S. P., Gleave, A. P., Green, A. G., and Waterhouse, P. M. 2001. Construct design for efficient, effective and high-throughput gene silencing in plants. Plant J. 27:581-590.

Zamore, P. D. 2001. RNA interference: Listening to the sound of silence. Nat. Struc. Biol. 8:746-750. 